\title{
DHEA reduces the palmitate-induced apoptosis in L6 myotubes
}

Vitor Felitti, Gabriela Moreira, Caio Jordão, Carla R. Carvalho

Department of physiology \& biophysics Biomedical Sciences Institute University of

São Paulo

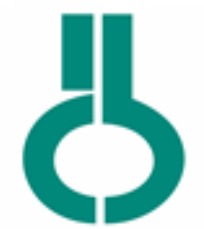

ICBUSP

\section{Introduction}

Dehydroepiandrosterone (DHEA) and its sulfated form (DHEAS) are the most abundant steroid in humans, produced mainly by the adrenal cortex, converted to androgens and estrogens in peripheral tissues by tissue-specific steroidogenic enzymes.

There are experimental evidences indicating DHEA anti-obesity, anti-inflammatory, and anti-oxidative effects in cell lines, animal models, and human.

\section{Objectives}

The aim of this study was analyze the protective effect of DHEA in the skeletal muscle cell line, L6 myotubes, treated with palmitate toward the AKT, mTORC1/p70S6k, and ATF4/GADD34 pathways.

\section{Methods}

Differenciated L6 myotubes were incubated with DHEA10nM or $100 \mathrm{nM}$ for 36 hours plus $0.5 \mathrm{mM}$ palmitate incubation for the last $12 \mathrm{~h}$.

The samples were used for typical immunoblotting with antibodies against the mentioned proteins above, and morphological analysis of cell death.

Data are represented as mean \pm error.

Statistical analyzes were performed using one-way ANOVA $(p<0.05)$

\section{Results}
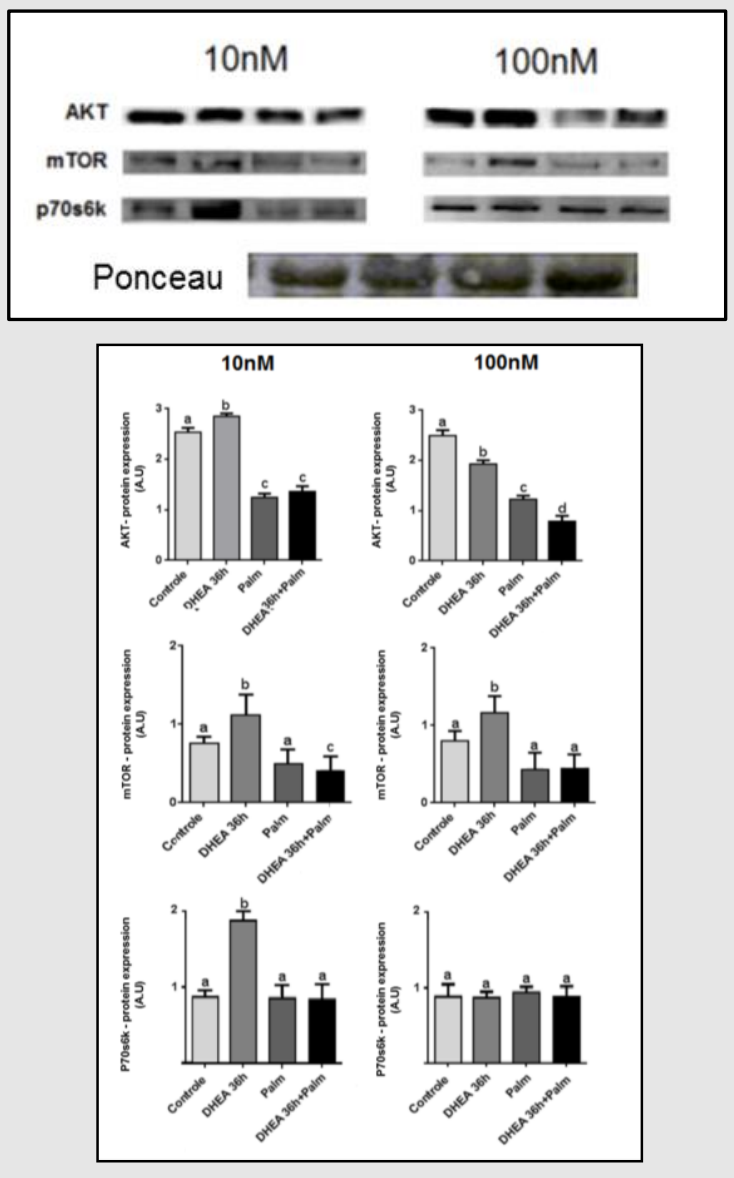

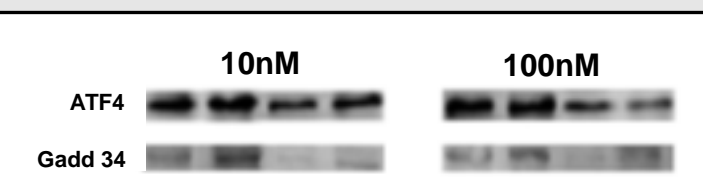

Ponceau

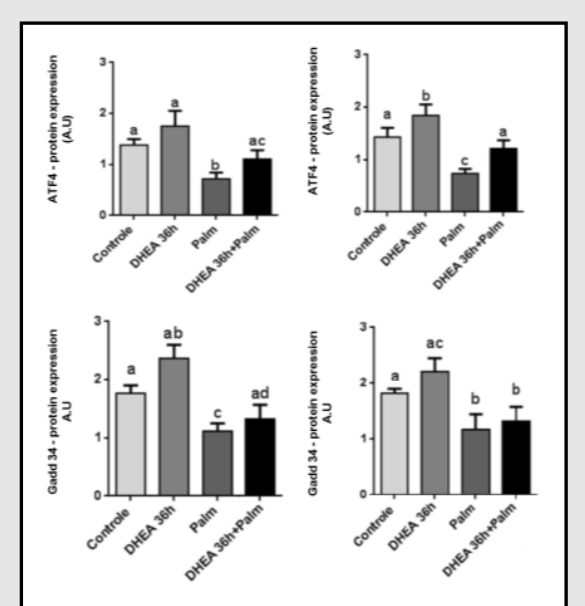

Morphological analysis of cell death

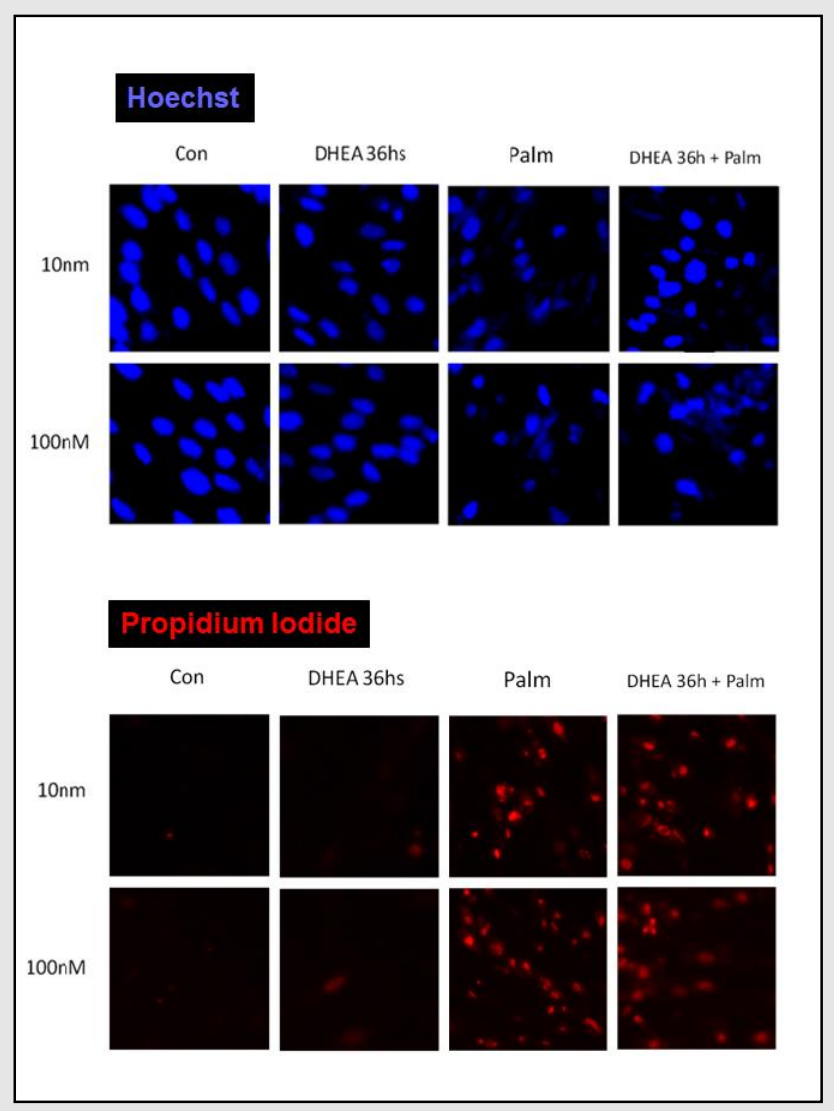

\section{Conclusion}

The physiological DHEA concentration was able to increase the expression of proteins involved in the both protein synthesis and UPR pathways.

It was also able to have a protective effect upon lipotoxicity.

Acknowledgment 